\title{
笈ESE
}

Revista Eletrônica dos Pós-Graduandos em Sociologia Política da UFSC

Vol. 5. n. 1 (1) agosto-dezembro/2008

ISSN $1806-5023$

\section{A questão da identidade em Giddens e Bauman}

\begin{abstract}
Alan Mocellim ${ }^{1}$
Resumo: Este artigo tem como objetivo debater as idéias de dois sociólogos contemporâneos, Anthony Giddens e Zygmunt Bauman, sobre a questão da identidade, e mais especificamente sobre a questão das auto-identidades num contexto de globalização. Partiremos de um esboço geral da relação entre modernidade e identidade para, a seguir, abordar o que ambos os autores pensam sobre o tema. Por fim, pretendese fazer uma breve relação entre as idéias de ambos.
\end{abstract}

Palavras-Chave: modernidade; identidade; Giddens; Bauman.

\begin{abstract}
This article has as objective to debate the ideas of two contemporary sociologists, Anthony Giddens and Zygmunt Bauman, on the question of the identity, and more specifically on the question of the self-identities in a globalization context. We will start with a general sketch of the relation between modernity and identity for, after that, approach what both authors think on the subject. Finally, is intended to make a brief relation between the ideas of both.
\end{abstract}

Key-Words: modernity; identity; Giddens, Bauman.

1 Alan Delazeri Mocellim é graduado em Ciências Sociais e mestrando em Sociologia Política (UFSC). E-mail para contato: a.mocellim@gmail.com

EmTese, Vol. 5 n. 1 (1), agosto-dezembro/2008, p. 01-31 


\section{留ESE}

Revista Eletrônica dos Pós-Graduandos em Sociologia Política da UFSC

Vol. 5. n. 1 (1) agosto-dezembro/2008

ISSN 1806-5023

É bastante recente a centralidade que a questão da identidade passou a ter nas ciências sociais. Seguindo a argumentação de Hall (1998) pode-se dizer que a identidade torna-se um problema ainda mais relevante num contexto em que as identidades não mais se referem à grupos fechados, ou apenas identidades étnicas. Num mundo instável - numa sociedade de risco (BECK, 2003), numa modernidade líquida (BAUMAN, 2001) - as identidades também se tornam instáveis. Deixam de ser determinadas por grupos específicos e também deixam de ser o foco de estabilidade do mundo social. As identidades tornam-se híbridas e deslocadas de um vínculo local. E isso significa também que são transformadas em uma tarefa individual, em um processo de construção incessante, e não mais de atribuição coletiva que implicava apenas certa conformação às normas sociais.

Por outro lado, outra discussão é acionada através do debate acerca das identidades: as fronteiras entre a psicologia e a sociologia. O deslocamento da identidade enquanto identificação cultural para construção individual opera um deslocamento nas fronteiras do que é objeto de uma ou outra ciência. Quando o self se torna objeto da sociologia, e quando o debate em torno do indivíduo se torna predominante, torna-se bastante sutil as fronteiras entre essas duas tradições científicas.

Esse artigo se propõe a debater as idéias de dois sociólogos contemporâneos: Anthony Giddens e Zygmunt Bauman. Ambos são nomes reconhecidos mundialmente no campo da sociologia, e têm intensa e produtiva obra, sendo grandes exemplos de como a questão da identidade ganhou força nas ciências 


\section{留ESE}

Revista Eletrônica dos Pós-Graduandos em Sociologia Política da UFSC

Vol. 5. n. 1 (1) agosto-dezembro/2008

ISSN 1806-5023

sociais. Tanto Giddens quanto Bauman dedicaram livros exclusivamente ao tema, e para ambos esse se torna um dos problemas teóricos mais relevantes numa sociedade globalizada. Partiremos de uma introdução que almeja caracterizar os principais aspectos da modernidade, de modo a inserir o tema da identidade, para, assim, debater as idéias de ambos os autores quanto ao tema. Por fim, e de modo a concluir, buscaremos estabelecer comparações entre as concepções de ambos os autores.

\section{Introdução: Modernidade e Identidade}

$\mathrm{O}$ que historicamente passamos a chamar de modernidade refere-se a um modo de vida, costumes, e organização social, que emergiu na Europa por volta do século XVII e que se tornou mundial rapidamente (GIDDENS, 1991). Segundo Giddens a modernidade pode ser entendida dentro de quatro dimensões, como a expansão de quatro formas institucionais, são elas: o capitalismo, o industrialismo, a vigilância e o poder militar.

O capitalismo pode ser entendido como "um sistema de produção de mercadorias, centrado sobre a relação entre propriedade privada do capital e o trabalho assalariado sem posse de propriedade, essa relação formando o eixo principal do sistema de classes" (GIDDENS, 1991, p.61). O capitalismo necessita de mercados competitivos, assim como investidores, produtores e consumidores. Juntos esses fatores o geram e o realimentam. 


\section{留ESE}

Revista Eletrônica dos Pós-Graduandos em Sociologia Política da UFSC

Vol. 5. n. 1 (1) agosto-dezembro/2008

ISSN 1806-5023

$\mathrm{O}$ industrialismo se refere ao processo de industrialização, ao surgimento das fábricas. Sua principal característica é "o uso de fontes inanimadas de energia material na produção de bens, combinado ao papel central da maquinaria no processo de produção" (GIDDENS, 1991, p.61).

A vigilância é relacionada à supervisão da população pelos que detêm o poder político. Trata-se de vigilância tanto direta - como as de que trata Foucault (2004; 2005), como prisões, escolas, etc. - como também indireta, baseada no controle da informação por especialistas, ou órgãos governamentais.

$\mathrm{O}$ que chamamos aqui de poder militar pode em grande parte ser descrito pelo que se nomeia de monopólio da violência. "O monopólio bem-sucedido dos meios de violência dentro de fronteiras territoriais precisas é específico do estado moderno. Como o é igualmente a existência de vínculos específicos com o industrialismo, permeando as organizações militares e os armamentos a sua disposição" (GIDDENS, 1991, p.64).

Todas essas quatro formas institucionais se entrelaçam para formar o que chamamos de modernidade. Todas elas atuam em conjunto, e uma fortalece a outra. E somente articuladas que podem fazer emergir uma economia capitalista mundial e a divisão do mundo pelo sistema de Estado-Nação.

A modernidade foi em grande parte também um projeto. Um projeto que tinha como meio o conhecimento, e como fim a organização e o controle do mundo. Diversos autores enunciam essa como uma característica fundamental do projeto 


\section{T⿱⺈ $\mathrm{TSE}$}

Revista Eletrônica dos Pós-Graduandos em Sociologia Política da UFSC

Vol. 5. n. 1 (1) agosto-dezembro/2008

ISSN 1806-5023

moderno. Adorno e Horkheimer (1985) denunciam o projeto moderno como um projeto que tendo como objetivo a libertação do homem de suas necessidades naturais, acabava por, libertando o homem da natureza, dominando-o pelos mesmos meios que o libertou. A dominação do homem pelo homem acabava por ser uma conseqüência da dominação do mundo, da natureza.

Para Bauman (1999) a "existência é moderna na medida em que contém a alternativa da ordem e do caos." Para ele a modernidade significou uma constante luta contra a ambivalência, uma busca incessante de formas de conhecer, classificar e ordenar o mundo. Tudo que não seja ordenado, nesse sentido, passa a ser considerado natural, e tudo que é natural, deve ser controlado e adequado às condições humanas de vida. Modernidade é sinônimo de ordem. O projeto moderno era um projeto de ordem, e por ser projeto não podia ser diferente. Esse projeto era o projeto científico-técnico de conhecer para controlar, e utilizar a favor dos homens. O projeto do Estado Moderno visava organizar os povos e a existência social de cada um deles, para assim lhes trazer uma vida melhor.

O Estado Moderno nasceu com a busca de uma sociedade racionalmente planejada. Buscou obstinadamente ordenar e classificar seu território, o deixando de acordo com seu projeto. "O projeto (...) fornecia os critérios para avaliar a realidade do dia presente. Esses critérios dividiam a população em plantas úteis a serem estimuladas e cuidadosamente cultivadas e ervas daninhas a serem removidas ou arrancadas." (BAUMAN, 1999, p.29) O projeto do Estado Moderno dividia a sociedade em categorias, as pessoas em grupos, e buscava através da razão fugir da indeterminação. A

EmTese, Vol. 5 n. 1 (1), agosto-dezembro/2008, p. 01-31 


\section{留ESE}

Revista Eletrônica dos Pós-Graduandos em Sociologia Política da UFSC

Vol. 5. n. 1 (1) agosto-dezembro/2008

ISSN 1806-5023

convergência de tal projeto com uma sociedade nacional moderna, em sua ânsia por ordenar, separava o mundo entre amigos e inimigos, os de dentro e os de fora.

Todo o projeto, e assim a forma de vida moderna, se fundamentava em uma concepção filosófica e científica de desenvolvimento, e na idéia de que a através da razão poderíamos alcançar a verdade. Filósofos e cientistas foram os grandes profetas e missionários da modernidade:

\footnotetext{
"A ciência moderna nasceu da esmagadora ambição de conquistar a Natureza e subordiná-la às necessidades humanas. A louvada curiosidade cientifica que teria levado os cientistas 'aonde nenhum homem ousou ir ainda' nunca foi isenta da estimulante visão de controle e administração, de fazer as coisas melhores do que são (isto é, mais flexíveis, obedientes, desejosas de servir)." (BAUMAN, 1999, p.48)
}

Esse era o projeto da sociedade moderna, do Estado moderno, e da ciência moderna, que acabaram por resultar no mundo globalizado-ocidental que conhecemos. A modernidade trouxe mudanças radicais ao mundo, mudanças que Giddens se referiu como conseqüências da modernidade (1991). Uma primeira dessas conseqüências foi uma mudança radical das concepções de espaço e tempo. Nas sociedades pré-modernas, espaço e tempo estavam plenamente relacionados, sempre foram vinculados no agir cotidiano. Com o advento da modernidade, com a invenção de relógios, de um calendário padronizado, e com a possibilidade de se deslocar por longos espaços em tempo reduzido, o tempo e o espaço se desconectaram, tiveram a dependência de um em relação ao outro reduzida. E assim, as ações humanas, com o espaço flexibilizado, passaram a repercutir fora dos contextos locais, atingindo o global: 


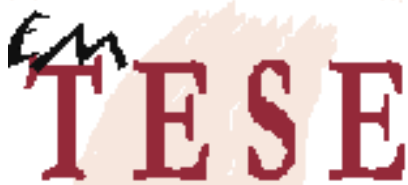

Revista Eletrônica dos Pós-Graduandos em Sociologia Política da UFSC

Vol. 5. n. 1 (1) agosto-dezembro/2008

ISSN $1806-5023$

\begin{abstract}
"O advento da modernidade arranca crescentemente o espaço do tempo fomentando relações entre outros 'ausentes', localmente distantes de qualquer situação dada ou interação face a face. (...) O que estrutura o lugar não é simplesmente o que está presente na cena; a 'forma visível' do local oculta relações distantes que determinam sua natureza." (GIDDENS, 1991, p.27)
\end{abstract}

A esse processo de deslocamento das relações sociais - uma das principais conseqüências da modernidade - de contextos locais para um contexto que articula distâncias indefinidas de tempo-espaço, Giddens se refere como desencaixe. Assim do desencaixe da dimensão local, vamos ao reencaixe das relações em âmbito local-global.

Porém, para haver desencaixe e reencaixe é necessário existirem sistemas peritos, e nesse sentido confiança em sistemas peritos. Os sistemas peritos são "sistemas de excelência técnica ou competência profissional que organizam grandes áreas dos ambientes material e social que vivemos hoje." (GIDDENS, 1991, p.35) Os sistemas peritos removem as relações sociais de contextos locais, específicos. Eles exigem confiança em sua eficácia, confiança que funciona como uma "fé" em seus prováveis resultados.

Outra grande característica da vida social moderna, segundo Giddens, é a acentuada reflexividade das práticas sociais. O que isso significa? Significa que as práticas sociais são "constantemente examinadas e reformuladas à luz de informação renovada sobre estas próprias práticas, alterando assim constutivamente seu caráter." (GIDDENS, 1991, p.45) A reflexividade inerente às práticas sempre existiu, mesmo nas sociedades pré-modernas, porém na modernidade ela se radicaliza, tendo por meio o conhecimento cientifico organizado e a propagação de informação por meios de 


\section{留ESE}

Revista Eletrônica dos Pós-Graduandos em Sociologia Política da UFSC

Vol. 5. n. 1 (1) agosto-dezembro/2008

ISSN 1806-5023

comunicação que atingem uma grande parte da população mundial em tempo relativamente curto.

Essas são características da sociedade moderna que nos permitem dizer que o mundo moderno é a primeira forma de existência verdadeiramente global, no sentido em que articula o local e o global, tendo o tempo controlado e espaço "minimizado".

Porém esse quadro a respeito da modernidade, que perdurou por muito tempo, está mudando. Vemos, cada vez mais, através do desenvolvimento de novos meios de comunicação, tendo como exemplo a Internet, e das diversas formas que fazem que nosso mundo se torne mais globalizado, para o bem ou para o mal, que estamos passando por um novo período, onde muitas das características da modernidade se acentuam, ou se modificam radicalmente. São diversos os nomes que são dados a essa possível nova fase da modernidade: pós-modernidade, modernidade tardia, altamodernidade, segunda modernidade, sociedade de risco, modernidade líquida. Porém, para além de tamanha confusão de termos e conceitos, existem algumas características gerais que dizem respeito a esse novo período.

Beck (2003) distingue algumas características fundamentais entre as duas modernidades, a primeira e a segunda. A primeira é profundamente marcada pelo Estado Nacional, e baseia-se numa clara distinção entre sociedade e natureza. Sendo a natureza "mero conceito daquilo que é estranho, daquilo que está fora da sociedade e precisa ser controlado" (BECK, 2003, p.21). Tratam-se também de sociedades do trabalho, onde a participação social se define pela participação no trabalho produtivo. Na segunda modernidade “a oposição natureza/sociedade torna-se questionável em 


\section{管ESE}

Revista Eletrônica dos Pós-Graduandos em Sociologia Política da UFSC

Vol. 5. n. 1 (1) agosto-dezembro/2008

ISSN 1806-5023

virtude da tecnologia intensificada e da crise ecológica" (BECK, 2003, p.24). Cada vez mais as vantagens trazidas pela industrialização trazem com elas grandes riscos. Além disso, essa segunda modernidade tem os processos de globalização - econômica, social, política, e cultural - intensificados por meio dos avançados meios de transporte e comunicação; assim como os processos de individualização, que faz com que as categorizações coletivas baseadas no trabalho já não expliquem muita coisa.

Giddens (2002) considera umas das principais características da modernidade tardia, como prefere chamar, a radicalização da reflexividade: cada vez mais as práticas sociais são revisadas mais rapidamente sob a luz de conhecimentos estes, agora, produzidos mais rapidamente e em maior quantidade. Essa radicalização da reflexividade torna a modernidade tardia ainda mais imprevisível, e impede qualquer possibilidade de ordenamento racional da sociedade e do meio ambiente. Os sistemas peritos atuam como um dos principais meios por onde atua essa reflexividade, e são, na busca de oferecer soluções especializadas para os problemas, um gerador de novos problemas, pois:

“(...) quanto mais um problema é colocado e foco, tanto mais as áreas circundantes de conhecimento se tornam embaraçadas para os indivíduos que delas se ocupam, e tanto menos é provável que eles sejam capazes de antever as consequências de sua contribuição para além da esfera particular de sua aplicação.” (GIDDENS, 2002, p.35)

Bauman (2001) chama de modernidade líquida essa nova fase da modernidade. Ele usa a idéia de liquidez em oposição da solidez, que seria a metáfora apropriada da primeira modernidade. Essa liquidez estaria invadindo todos os setores da 


\section{管ESE}

Revista Eletrônica dos Pós-Graduandos em Sociologia Política da UFSC

Vol. 5. n. 1 (1) agosto-dezembro/2008

ISSN 1806-5023

modernidade que antes eram sólidos. A economia se desterritorializou, e se tornou independente do local, o trabalho que antes era localizado, e vigiado em grandes fábricas, hoje é flexível, não depende mais da produção de bens materiais, não depende da localidade onde são produzidos, e muitas vezes nem mesmo dos que trabalham esses passam a ser mão-de-obra flexível, cada vez com menos direitos trabalhistas. O poder que antes dependia da localidade também se tornou fluído, hoje não é necessário estar num local para manter ele sob controle, a própria distância e o nomadismo se tornaram estratégias de poder. Em meio a isso, o indivíduo se torna cada vez mais apto a escolher "livremente", dentre as opções que o mercado dispõe ao consumo. Suas possibilidades são infinitas, mas isso não faz dos indivíduos mais felizes: em meio a tantas possibilidades, as conseqüências de uma má escolha recaem sobre o indivíduo, não existem mais bases sólidas nas quais se apoiar caso tomem uma má decisão.

Enfim, todos esses autores evidenciam que uma grande mudança está em curso na atualidade, e se torna cada vez mais radical a cada deslocamento do tempo e do espaço de suas dimensões tradicionais. E assim, as identidades nesse novo período também se tornam diferentes das identidades sólidas da primeira modernidade.

Segundo Hall "as velhas identidades, que por tanto tempo estabilizaram o mundo social, estão em declínio, fazendo surgir novas identidades e fragmentando o indivíduo moderno, até aqui visto como sujeito unificado." (HALL, 1998, p.7) Para ele as mudanças estruturais que tiveram inicio nas sociedades modernas no fim do século XX estão transformando com elas as idéias que temos de sujeito, e nossas formas de "exercer" uma identidade. 


\section{T⿱⺈ $\mathrm{TSE}$}

Revista Eletrônica dos Pós-Graduandos em Sociologia Política da UFSC

Vol. 5. n. 1 (1) agosto-dezembro/2008

ISSN 1806-5023

Hall (1998) distingue três concepções bastante diferentes de identidade, cada uma equivalente a um período histórico - sendo reflexo de um momento social e de formas de pensar específicas de sua época - são elas:
a) sujeito do Iluminismo
b) sujeito sociológico
c) sujeito pós-moderno

O sujeito do Iluminismo era baseado na idéia de ser humano autônomo, único, centrado, unificado e coerente. Segundo essa visão todos os homens eram dotados de razão e agiam racionalmente. $\mathrm{E}$ as identidades eram coerentemente, e racionalmente construídas. Era também uma visão muito individualista do sujeito e de sua identidade. Podemos encontrar essa visão nos trabalhos de René Descartes e John Locke, assim como na visão da economia política clássica, tendo como exemplo Adam Smith.

O sujeito sociológico nasceu com as mudanças complexas pelas quais passavam as sociedades modernas. É uma visão que surgiu por volta do fim do século XIX, mas se tornou muito aceita durante meados do século XX. Essa visão consistia na descoberta que o sujeito não era autônomo como se imaginava, que ele não poderia ser auto-suficiente, e de que sua identidade era construída num diálogo incessante com as pessoas da sociedade em que vive. O sujeito ainda tem sua individualidade, um "eu interior", só que esse é formado, e transformado, de acordo com as experiências do indivíduo no meio social. É uma noção de identidade que depende de uma estrutura social, e que não pode ser constituída independentemente dela. Podemos encontrar essa 


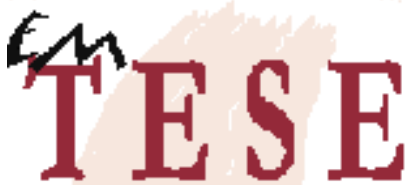

Revista Eletrônica dos Pós-Graduandos em Sociologia Política da UFSC

Vol. 5. n. 1 (1) agosto-dezembro/2008

ISSN 1806-5023

noção se desenvolvendo, inicialmente, nos trabalhos de Durkheim, e pode-se dizer que também nos de Marx e mesmo Freud, mas ela chega a seu auge nos trabalhos dos interacionistas simbólicos, como Goffmann e Garfinkel.

Porém, desde o fim do século XX, tem sido argumentado que essas noções de auto-identidade não correspondem mais a realidade. Hall argumenta que:

\begin{abstract}
"O sujeito, previamente vivido como tendo uma identidade unificada e estável, está se tornando fragmentado; composto não de uma única, mas de várias identidades, algumas vezes contraditórias e não resolvidas. Correspondentemente, as identidades, que compunham as paisagens sociais 'lá fora' e que asseguravam nossa conformidade subjetiva com as 'necessidades' objetivas da cultura, estão entrando em colapso, como resultado de mudanças estruturais e institucionais. $\mathrm{O}$ próprio processo de identificação, através do qual nos projetamos em nossas identidades culturais, tornou-se mais provisório, variável e problemático." (HALL, 1998, p.12)
\end{abstract}

Tudo isso acontece em meio a um momento de intensa globalização. O desenvolvimento incessante das tecnologias de transporte e comunicação, cada vez mais liga o local ao global. A maior interdependência global leva a um colapso das identidades tradicionais, ligadas ao local, e produz uma diversidade cada vez maior de estilos e identidades (HALL, 1998). E se por um lado, o acesso a informações provenientes de muitos lugares do mundo hibridiza, por outro também homogeneíza, é um processo duplo. De um lado os locais, se misturam, e identidades que antes eram locais podem ser encontradas agora em qualquer local. De outro, certos padrões se encontram em todos lugares, padrões que se relacionam ao consumo:

"Os fluxos culturais, entre as nações, e o consumismo global criam possibilidades de 'identidades partilhadas' - como 'consumidores' para os mesmos bens, 'clientes' para os mesmos serviços, 'públicos' para as mesmas 


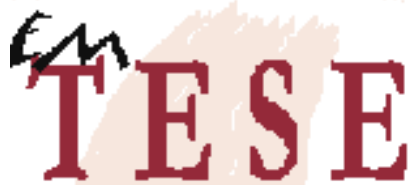

Revista Eletrônica dos Pós-Graduandos em Sociologia Política da UFSC

Vol. 5. n. 1 (1) agosto-dezembro/2008

ISSN 1806-5023

mensagens e imagens - entre pessoas que estão bastante distantes umas das outras no espaço e no tempo." (HALL, 1998, p.74)

E ainda:

\begin{abstract}
"Quanto mais a vida social se torna mediada pelo mercado global de estilos, lugares e imagens, pelas viagens internacionais, pelas imagens da mídia e pelos sistemas de comunicação globalmente interligados, mais as identidades se tornam desvinculadas - desalojadas - de tempos, lugares, histórias e tradições específicos e parecem 'flutuar livremente'." (HALL, 1998, p.75)
\end{abstract}

Assim, a globalização inclui processos que hibridizam - colocando culturas, formas de ser, estilos de vida, um de frente com o outro - e processos que homogeneízam - negando o local em favor de um global destituído de ambiguidade, num processo de padronização radical. As culturas locais se inter-relacionam, e solapam assim sua localidade, ao mesmo tempo em que adotam uma cultura que partilham globalmente como consumidores, freqüentando shoppings e supermercados, andando por estradas ou aeroportos. É nesse sentido que encontramos em Augé (1994) a consideração de que a vida urbana contemporânea é produtora de não-lugares, espaços que não podem ser traduzidos por vínculos identitários, relacionais ou históricos lugares de fluxo, de transição, por onde a passagem é fugidia. São lugares que não mais definem as identidades pelas relações sociais que neles se estabelecem, são lugares destinados à passagem, à negação dos vínculos relacionais.

Debatemos aqui algumas das mudanças radicais pelas quais passam as sociedades nesse inicio de século XXI - mudanças essas que começaram a seguir esse caminho a cerca de trinta anos - e suas conseqüências para as formas de identidade que 


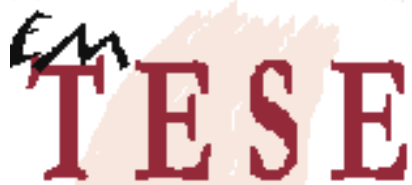

Revista Eletrônica dos Pós-Graduandos em Sociologia Política da UFSC

Vol. 5. n. 1 (1) agosto-dezembro/2008

ISSN 1806-5023

emergem atualmente. Iremos, nos tópicos seguintes, nos aprofundar em algumas questões específicas sobre as identidades na modernidade.

\section{Giddens: Identidade, Reflexividade e Estilos de Vida}

Diversos são os fatores que contribuem para o dinamismo da modernidade tardia. Entre eles podemos citar a separação do tempo e espaço - que permite a articulação de relações sócias em amplos intervalos de tempo espaço, do local ao global -, os mecanismos de desencaixe - fichas simbólicas e sistemas peritos, que em conjunto separam as relações das particularidades de uma relação local - e a reflexividade - o uso de conhecimento constantemente reformulado sobre a vida social. (GIDDENS, 2002) Todos estes fatores têm grandes conseqüências para o eu e para as identidades. Podemos dizer que agora as identidades deixam de ser localizadas, ou relacionadas a grupos locais, elas se tornam globais, dialogam com o global a todo tempo. A reflexividade, seja através do conhecimento perito ou da mediação da experiência pelos meios de comunicação, contribui para isso de maneira radical. Somos expostos a novas informações, que podem levar a reformulação de nós mesmos e de nossas práticas sociais.

Giddens (2002, p.74) acredita que dizer que a questão da auto-identidade é um problema moderno originado no individualismo ocidental é uma forma muito simplista de falar sobre as identidades. Giddens ressalta que a questão da identidade, assim como a individualidade, sempre foram questões presentes mesmo nas culturas tradicionais, pré-modernas. Para ele é necessário explicar melhor o que a modernidade, 


\section{留ESE}

Revista Eletrônica dos Pós-Graduandos em Sociologia Política da UFSC

Vol. 5. n. 1 (1) agosto-dezembro/2008

ISSN 1806-5023

e em especial a modernidade tardia, traz de diferente sobre a forma como as pessoas pensam, constroem e vivem suas identidades.

Giddens (2002) responde essa questão elucidando as características centrais desse eu e dessas identidades, características que estão presentes, por exemplo, no discurso dos livros de auto-ajuda, ou auto-terapia. Esses livros trazem a tona toda uma narrativa sobre o eu na modernidade tardia, deixando claro que "O que fazer?", "Como agir?", e “Quem ser?” são questões cada vez mais importantes e presentes no nosso cotidiano. Giddens (2002, p.74-79) enumera 10 características referentes à autoidentidade na modernidade tardia que podem ser verificadas no discurso da auto-terapia - que para ele, apesar da parcialidade, é bastante representativo do discurso contemporâneo sobre a identidade.:

1- “O eu é visto como um projeto reflexivo, pelo qual o indivíduo é responsável”. (GIDDENS, 2002, p.74) Somos o que fazemos de nós. O que uma pessoa se torna depende das ações nas quais se envolve, nas escolhas quanto ao que deve ou não fazer.

2- O eu é construído tendo por base o passado, mas visando o futuro. "O indivíduo apropria seu passado peneirando-o à luz do que antecipa como um futuro." (GIDDENS, 2002, p.75) A trajetória do eu depende da coerência do discurso à respeito do passado, depende da apropriação do passado para objetivos futuros.

3- A reflexividade da auto-identidade nunca cessa. De tempos em tempos nos perguntamos sobre o que estamos fazendo. E com base nas respostas que conseguimos reformulamos a forma como agimos. 


\section{T⿱⺈ $\mathrm{ESE}$}

Revista Eletrônica dos Pós-Graduandos em Sociologia Política da UFSC

Vol. 5. n. 1 (1) agosto-dezembro/2008

ISSN 1806-5023

4- A construção de uma identidade coerente depende de uma narrativa sobre si. A autobiografia é assim um fator central para as identidades na vida social moderna.

5- "O futuro é pensado como cheio de possibilidades, mas não aberto ao livre jogo das contingências. Tanto quanto possível, o futuro deverá ser ordenado exatamente por aqueles processos de controle temporal e interação ativa de que depende a integração da narrativa do eu.” (GIDDENS, 2002, p.76) O controle do tempo se torna essencial para a organização do futuro, para a satisfação pessoal, e para a construção de uma identidade coerente.

6- A reflexividade afeta também o corpo. O corpo é apresentado como uma forma de construir um eu diferenciado. "Experimentar o corpo é uma maneira de tornar coerente o eu como um todo integrado, uma maneira do indivíduo dizer 'é aqui que vivo"”. (GIDDENS, 2002, p.76)

7- A auto-realização depende do enfrentamento de determinados riscos, e do equilíbrio entre riscos e oportunidades. "O indivíduo deve enfrentar novos riscos decorrentes da ruptura com os padrões estabelecidos de comportamento inclusive o risco de que as coisas possam ficar piores do que estavam". (GIDDENS, 2002, p.77)

8- A auto-realização depende da autenticidade - no ser verdadeiro consigo mesmo. Temos que permanentemente enfrentar desafios que nos impedem de compreender a nós mesmos como realmente somos.

9- A vida, e a narrativa de si, é composta de diversas "passagens" não institucionalizadas. Passar por um período de transição significativo - por um momento decisivo - significa aceitar e correr riscos para assim ter acesso a novas oportunidades. 


\title{
留ESE
}

Revista Eletrônica dos Pós-Graduandos em Sociologia Política da UFSC

Vol. 5. n. 1 (1) agosto-dezembro/2008

ISSN 1806-5023

10- A realização de um eu autêntico depende da integração das experiências da vida cotidiana com a narrativa do auto-desenvolvimento individual. A história de vida é construída e reconstruída com base no que vivemos e no que buscamos.

As condições modernas de vida fazem com que os indivíduos se deparem com uma grande variedade de escolhes. Uma dessas escolhas se refere ao estilo de vida:

\begin{abstract}
“(...) nas condições da alta modernidade, não só seguimos estilos de vida, mas num importante sentido somos obrigados a faze-lo - não temos escolha senão escolher. Um estilo de vida pode ser definido como um conjunto mais ou menos integrado de práticas que um indivíduo abraça, não só porque essas práticas preenchem necessidades utilitárias, mas porque forma material a uma narrativa particular da auto-identidade." (GIDDENS, 2002, p.79)
\end{abstract}

Os estilos de vida são ligados a rotinas cotidianas: formas de comer, formas de vestir, modos de agir, lugares freqüentados. Porém as rotinas estão sempre abertas a mudanças. Cada pequena decisão que é tomada no nosso cotidiano contribui para a alteração dessas rotinas, e, portanto, para a reformulação do eu. São escolhas sobre como agir e sobre quem ser.

$\mathrm{Na}$ alta modernidade dispomos de uma pluralidade escolhas em relação ao nosso estilo de vida. Isso não significa que todas as possibilidades estão abertas para todos, nem que as pessoas façam suas escolhas sabendo de todas alternativas disponíveis. A seleção estilos de vida é influenciada em grande parte por pressões de grupo e pela visibilidade de determinados estilos, ou limitada a determinadas condições socioeconômicas. (GIDDENS, 2002, p.81) 


\section{留ESE}

Revista Eletrônica dos Pós-Graduandos em Sociologia Política da UFSC

Vol. 5. n. 1 (1) agosto-dezembro/2008

ISSN 1806-5023

Além disso, a pluralidade de escolhas quanto aos estilos de vida tem por base diversas características específicas:

1- Escolhas plurais - a possibilidade de escolher entre diversas alternativas possíveis - isto é, a tradição já não é determinante na escolha de estilos de vida, o indivíduo agora pode optar, dentro de determinados limites acima comentados, por estilos bastante diferenciados.

2- A vida moderna pressupõe a interação social em ambientes bastante diversos. Certos estilos de vida estão fortemente ligados a alguns ambientes específicos. Também em parte da diversidade de ambientes onde interagir as escolhas individuais tendem a ser fragmentadas, pois modos de agir e de ser que são necessários em determinados ambientes são dispensáveis em outros.

3- A reflexividade nos leva a viver numa situação de dúvida metódica. Com o conhecimento sendo constantemente reformulado fica difícil decidir sobre como agir. E os mesmos problemas podem ter diversas formas de resolução.

4- As experiências transmitidas pela mídia influenciam as escolhas de diversas maneiras. A mídia oferece acesso a possibilidades, ambientes, e estilos de vida antes desconhecidos; e ao mesmo tempo ajuda a diminuir as diferenças entre ambientes antes afastados e modos de vida bastante diferentes.

Diante de variadas alternativas de estilos de vida, um planejamento de vida assume grande importância. As pessoas tendem a não só optar por um estilo para responder a pergunta "Quem sou eu?", mas junto do estilo adotam um planejamento de vida com o qual poderão responder "Quem serei no futuro?". Nas palavras de Giddens (2002, p.83): 


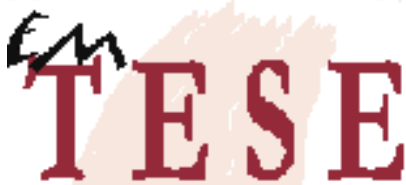

Revista Eletrônica dos Pós-Graduandos em Sociologia Política da UFSC

Vol. 5. n. 1 (1) agosto-dezembro/2008

ISSN 1806-5023

\begin{abstract}
“O planejamento de vida pressupõe um modo específico de organizar o tempo porque a construção reflexiva da auto-identidade depende tanto da preparação para o futuro quanto da interpretação do passado, embora 'retrabalhar' os eventos passados seja sempre importante nesse processo."
\end{abstract}

Uma outra "parte" importante da identidade individual que é afetada fortemente pela reflexividade é o corpo - que, para Giddens, inclui aparência, postura, e sensualidade. A aparência é conjunto de características da superfície de um corpo (incluindo modos de vestir); a postura é a forma como a aparência é utilizada pelos indivíduos nos ambientes nos quais se passam as atividades cotidianas; e a sensualidade é a forma como o corpo é utilizado em relação ao prazer e a dor. Ao contrário das culturas pré-modernas, temos relativa liberdade de escolha a respeito dos modos de se vestir. Digo relativa porque apesar de termos mais liberdade de escolha quanto à vestimenta, muitas situações sociais, ou posições específicas, assim como pressões de grupo e recursos econômicos, limitam esse tipo de escolha. A postura é bastante influenciada pela pluralização dos ambientes de interação; temos de interagir de modos diferentes em uma grande gama de espaços diferentes. A possibilidade de manter uma postura constante nos mais diversos onde possa se desenrolar uma interação é um dos meios mais importantes pelos quais se constrói uma auto-identidade coerente. (GIDDENS, 2002, p.95-96)

\footnotetext{
"Nos ambientes pós-tradicionais da alta modernidade, nem a aparência nem a postura podem ser consideradas definitivas; o corpo participa de maneira muito direta do princípio de que o eu deve ser construído. Regimes corporais, que também se referem diretamente aos padrões de sensualidade, são o meio principal pelo qual a reflexividade institucional da vida social moderna se centra no cultivo - quase se poderia dizer na criação - do corpo." (GIDDENS, 2002, p.96)
} 


\section{T⿱⺈ $\mathrm{ESE}$}

Revista Eletrônica dos Pós-Graduandos em Sociologia Política da UFSC

Vol. 5. n. 1 (1) agosto-dezembro/2008

ISSN 1806-5023

A construção das identidades reflexivamente também implica em alguns dilemas. Giddens (2002, p.175-186) descreve 4 dilemas fundamentais nesse processo.

O primeiro dilema é o entre a unificação e fragmentação. Desde o nível local ao global, as tendências à dispersão se opõem as tendências à integração. A unificação aqui se refere à construção de uma narrativa coerente sobre si diante das mudanças promovidas pela globalização. A fragmentação significa uma diversificação dos contextos de interação. Esse dilema se resolve com o uso da diversidade para a criação de uma identidade que incorpore os diferentes contextos numa narrativa integrada, fazendo dos diversos "eus" um só.

O segundo dilema é o entre a impotência e a apropriação. Temos hoje grandes oportunidades de nos apropriar de diversas formas de vida, de interagir em diversos ambientes, e de nos tornarmos bastante diferenciados (em comparação com as sociedades pré-modernas), porém junto com essas vantagens trazidas pela globalização, temos que lidar com situações em que o sentimento de impotência se amplia; diante de determinadas instituições de alcance global e dos riscos globais de altas conseqüências a sensação de impotência se radicaliza.

O terceiro dilema é o que contrapõe autoridade e incerteza. Nas condições atuais de vida, em quase todo o ocidente, não existem autoridades definitivas, a tradição já não tem poder como fonte primeira de autoridade. Vivemos hoje diante de um pluralismo de autoridades. A ciência, a religião, os governos, todos participam de decisões sobre temas que se cruzam e inter-relacionam. Essa pluralidade fornece várias 


\section{留ESE}

Revista Eletrônica dos Pós-Graduandos em Sociologia Política da UFSC

Vol. 5. n. 1 (1) agosto-dezembro/2008

ISSN 1806-5023

opções aos indivíduos, mas os colocam diante das incertezas que diversas visões, muitas vezes opostas, fazem surgir quando se busca fazer a melhor das escolhas.

O quarto dilema é o da experiência personalizada versus experiência mercantilizada. Determinados padrões de consumo promovidos pela propaganda influenciam a formação das identidades e promovem certos estilos de vida. A publicidade busca estimular estilos de vida que condizem com padrões de consumo que visam estabelecer. Assim, muitas vezes, o projeto reflexivo de se construir uma identidade se traduz na posse de determinados bens. Os meios de comunicação de massa apresentam estilos de vida aos quais deve-se aspirar. Porém nem tudo é mercantilização. As pessoas tendem a reagir criativamente, e seletivamente, a esses processos. Os indivíduos selecionam ativamente que tipo de informação é importante, e as interpretam de forma particular. A mercantilização não é apenas padronização ou homogeneização, é algo que promove a possibilidade de pluralidade de escolhas. As pessoas mesmo se utilizando de produtos de consumo de massa, ainda assim tomam decisões e reinterpretam essa utilização da sua própria maneira.

\section{Bauman: Identidade, Liquidez e Ambivalência}

As identidades, durante a modernidade, em oposição ao período prémoderno, se tornaram uma questão de construção, de esforço individual. Durante o período anterior a modernidade elas eram uma atribuição, você era algo e ponto final, não havia opção, ou mesmo esforço capaz de mudar isso. A modernidade inaugurou um 


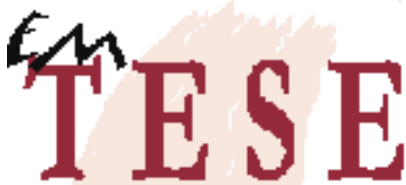

Revista Eletrônica dos Pós-Graduandos em Sociologia Política da UFSC

Vol. 5. n. 1 (1) agosto-dezembro/2008

ISSN 1806-5023

novo período. A modernidade transformou a identidade em questão de realização. Era o esforço individual que fazia a diferença:

\begin{abstract}
“O projeto moderno prometia libertar o indivíduo da identidade herdada. Não tomou, porém, uma firme oposição contra a identidade como tal, contra se ter uma identidade, mesmo uma sólida exuberante e sólida identidade. Só transformou a identidade, que era questão de atribuição, em realização fazendo dela, assim, uma tarefa individual e da responsabilidade do indivíduo." (BAUMAN, 1998, p.30)
\end{abstract}

Mesmo rompendo com a identidade atribuída a modernidade não rompeu com as identidades sólidas, coesas, e mesmo fixas, apenas começou a considerar válido, e obrigatório, o esforço para construí-las, sob a ressalva de que após adquirir uma identidade era muito difícil dela se desvencilhar.

A identidade durante a modernidade era vivida como projeto de vida, e assim devia ser construída vagarosamente, com muito esforço, com o objetivo de chegar a um ponto final:

\footnotetext{
“A construção requeria uma clara percepção da forma final, o cálculo cuidadoso dos passos que levariam a ela, o planejamento a longo prazo e a visão através de conseqüências de cada movimento. Havia, assim, um vínculo firme e irrevogável entre a ordem social como projeto e a vida individual como projeto, sendo a última impensável sem a primeira. (BAUMAN, 1998, p.31)
}

Assim como o projeto moderno foi uma questão de eliminação da ambivalência, de classificação e ordenamento incessante, as identidades na modernidade também seguiram esse mesmo caminho. Apesar de se tornarem identidades construídas, essas tinham um fim, e deviam ser bem definidas, e após 


\title{
T⿱⺈ $\mathrm{ESE}$
}

Revista Eletrônica dos Pós-Graduandos em Sociologia Política da UFSC

Vol. 5. n. 1 (1) agosto-dezembro/2008

ISSN 1806-5023

definidas imutáveis. Qualquer identidade que não fosse clara, ou que não pudesse se situar claramente em de uma forma ou outra - "ficando em cima do muro" - passava a ser considerada um problema. (BAUMAN, 1999)

Bauman $(1998,1999,2001,2003)$ afirma que hoje esse contexto não é mais válido. Estamos vivendo em um período onde esse medo da ambivalência quanto às identidades não existe mais. Hoje a própria ambivalência se torna um valor. Num mundo onde tudo é transitório, uma identidade fixa e bem definida não parece ser muito atrativa. Segundo Bauman (1998, p.112-113):

\begin{abstract}
"O mundo construído de objetos duráveis foi substituído pelo de produtos disponíveis projetados para imediata obsolescência. Num mundo como esse, as identidades podem ser adotadas e descartadas como uma troca de roupa. $\mathrm{O}$ horror da nova situação é que todo diligente trabalho de construção pode mostrar-se inútil; e o fascínio da nova situação, por outro lado, se acha no fato de não estar comprometida por experiências passadas, de nunca ser irrevogavelmente anulada, sempre "mantendo as opções abertas"”.
\end{abstract}

Manter as opções abertas significa aqui não se apegar a nada, nem a ninguém. Não se deixar levar por nenhum tipo de forma de vida durável suficientemente para se tornar um tédio:

\footnotetext{
"E desse modo a dificuldade já não é descobrir, inventar, construir, convocar (ou mesmo comprar) uma identidade, mas como impedi-la de ser demasiadamente firme e aderir depressa demais ao corpo. (...) O eixo da estratégia de vida pós-moderna não é fazer a identidade deter-se - mas evitar que se fixe." (BAUMAN, 1998, p.114)
}

Vivemos num mundo em que a durabilidade não é mais um valor tão importante como no passado. A ação e mesmo trabalho cada vez mais se tornam 


\section{T⿱⺈ $\mathrm{TSE}$}

Revista Eletrônica dos Pós-Graduandos em Sociologia Política da UFSC

Vol. 5. n. 1 (1) agosto-dezembro/2008

ISSN 1806-5023

secundários ao labor (ARENDT, 1991), e o consumo assim se torna o grande valor. Tudo deve ser consumido, e tudo deve ser descartável para ser consumido. Num mundo que, diferente da modernidade sólida, não se organiza mais em torno do trabalho, e sim em torno do consumo, as identidades se tornam também algo a ser consumido. E o consumo passa a ser o meio pelo qual são construídas as identidades.

Bauman (2001) opõe a vida organizada em torno do trabalho e da produção e em torno do consumo. A organizada em torno da produção tende a ser normativamente regulada, é necessária uma conformidade com determinadas regras para exercer seu papel na cadeia produtiva de forma correta. A vida organizada em torno do consumo, por outro lado, dispensa as normas: a sedução e o desejo se tornam os únicos fatores importantes. Essa vida orientada pelo consumo faz com que as identidades sejam apenas construídas por meio do consumo. O consumo, movido pelo desejo a ser saciado, volátil, de curto prazo, serve como padrão agora às identidades. É o produto e o produtor, fruto e semente dos mesmos processos que fazem a identidade se tornar líquida.

\footnotetext{
"Em vista da volatilidade e instabilidade intrínsecas de todas ou quase todas as identidades, é a capacidade de 'ir às compras' no supermercado das identidades, o grau de liberdade genuína ou supostamente genuína de selecionar a própria identidade e de mantê-la enquanto desejado, que se torna o verdadeiro caminho para a realização das fantasias da identidade. Com essa capacidade somos livres para fazer e desfazer identidades à vontade. Ou assim parece." (BAUMAN, 2001, p.98)
}

E continua: 


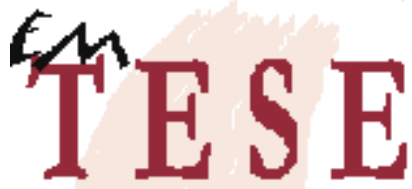

Revista Eletrônica dos Pós-Graduandos em Sociologia Política da UFSC

Vol. 5. n. 1 (1) agosto-dezembro/2008

ISSN $1806-5023$

\begin{abstract}
"Numa sociedade de consumo, compartilhar a dependência de consumidor - a dependência universal das compras - é a condição sine qua non de toda liberdade individual; acima de tudo da liberdade de ser diferente, de 'ter identidade"” (BAUMAN, 2001, p.98)
\end{abstract}

Assim, construímos nossas identidades pelo consumo de bens. E as próprias identidades passam ter características similares aos bens de consumo. Passam a ser identidades transitórias, descartáveis, e dispensáveis após a satisfação.

Uma outra mudança significativa, em relação à modernidade sólida, para a forma como são construídas as identidades no período liquido da modernidade, é a mudança nas concepções de corpo. "Se a sociedade dos produtores coloca a saúde como o padrão que seus membros devem atingir, a sociedade dos consumidores acena aos seus com o ideal da aptidão (fitness)". (BAUMAN, 2001, p.91)

A saúde se refere ao estado desejável do corpo, pressupõe um estado desejável, um estado normal. É uma condição física que permite ao indivíduo exercer seu papel social. Ao contrário da saúde, a aptidão significa ter um corpo flexível, ajustável, pronto para novas sensações, a agir de formas diferentes, um corpo adaptável as mais diversas situações. Aptidão significa fugir do rotineiro, e por isso elimina a idéia de normalidade. Se a saúde significa seguir as normas, aptidão significa superar as normas. A aptidão exige um auto-exame constante, e auto-recriminação permanente, nunca se chega ao ponto que se deseja. A saúde não resiste como valor em uma sociedade onde todas as normas são abaladas e substituídas periodicamente. O normal de ontem é empecilho hoje. O cuidado com o corpo hoje, mesmo disfarçado como saúde, segue o padrão da aptidão, do estar pronto a novas experiências e possibilidades, 


\section{TSES}

Revista Eletrônica dos Pós-Graduandos em Sociologia Política da UFSC

Vol. 5. n. 1 (1) agosto-dezembro/2008

ISSN 1806-5023

e de uma insatisfação constante com as possibilidades atuais. (BAUMAN, 2001, p.91-94)

Para Bauman (2003) a identidade surge como substituta da comunidade. Ela substitui a comunidade das normas, regras, padrões de conduta, e conforto, pela falta de conforto de um mundo sem padrões sólidos, onde a identificação se torna fugidia e frágil.

\footnotetext{
"Identidade significa aparecer: ser diferente e, por essa diferença, singular - e assim a procura da identidade não pode deixar de dividir e separar., no entanto a vulnerabilidade das identidades individuais e a precariedade da solitária construção da identidade levam os construtores da identidade a procurar cabides em que possam, em conjunto, pendurar seus medos e ansiedades individualmente experimentados e depois disso, realizar ritos de exorcismo em companhia de outros indivíduos também assustados e ansiosos." (BAUMAN, 2003, p.21)
}

A identidade como substituta da antiga forma de comunidade faz com que passe a existir uma nova forma de comunidade: as cloakroom communities, ou comunidades cabide (BAUMAN, 2001; 2003). Essas são comunidades voláteis, passageiras, destinadas a um ou alguns poucos aspectos, são comunidades voltadas a interesses específicos. Esse tipo de comunidade - ao contrário das comunidades da modernidade sólida, que se agrupavam em torno de interesses comuns e duráveis - se forma em torno de eventos e espetáculos, e dificilmente conseguem fundir interesses individuais em interesses de grupo (BAUMAN, 2001, p.227-230).

A construção da identidade é um processo que não tem fim ou destino, e no qual os objetivos se transformam antes mesmo de serem alcançados. A construção da 


\title{
T⿱⺈ $\mathrm{ESE}$
}

Revista Eletrônica dos Pós-Graduandos em Sociologia Política da UFSC

Vol. 5. n. 1 (1) agosto-dezembro/2008

ISSN 1806-5023

identidade é sempre um projeto incompleto. As comunidades devem ser sempre flexíveis, o corpo do construtor de identidade deve ser flexível, e suas atitudes sempre mutáveis e readaptáveis. A comunidade do período líquido da modernidade deve assim estar de acordo com essa nova identidade:

\begin{abstract}
“A 'comunidade', cujos usos principais são confirmar, pelo poder do número, a propriedade de escolha e emprestar parte de sua gravidade a que confere 'aprovação social', deve possuir os mesmos traços. Ela deve ser tão fácil de decompor como foi fácil de construir. Deve ser e permanecer flexível, nunca ultrapassando o nível 'até nova ordem' e 'enquanto for satisfatório", (BAUMAN, 2003, p.62)
\end{abstract}

As comunidades criadas em torno dessa idéia de identidade passam a ser comunidades estéticas - e não comunidades éticas como as comunidades que giram em torno de normas e objetivos, e destinos partilhados. As comunidades estéticas são reunidas em torno do entretenimento, de celebridades, de ídolos, Essas comunidades estéticas, comunidades cabide, cloakroom communities, dificilmente favorecem laços duradouros entre seus membros:

\footnotetext{
"Uma coisa que a comunidade estética definitivamente não faz é tecer entre seus membros uma rede de responsabilidades éticas e, portanto, de compromissos a longo prazo. Quaisquer que sejam os laços estabelecidos na explosiva e breve vida da comunidade estética, eles não vinculam verdadeiramente: eles são literalmente 'vinculos sem consequências'. (...) Como as atrações disponíveis nos parques temáticos, os laços das comunidades estéticas devem ser 'experimentados', e experimentados no ato - não levados para casa e consumidos na rotina diária.” (BAUMAN, 2003, p.67-68)
}

Bauman (1999, p.263) sugere que essas comunidades estéticas geradas pela busca de identidade, pela constante auto-definição individual, se assemelham as neo- 


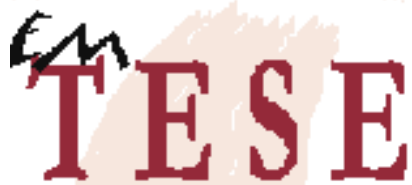

Revista Eletrônica dos Pós-Graduandos em Sociologia Política da UFSC

Vol. 5. n. 1 (1) agosto-dezembro/2008

ISSN 1806-5023

tribos de Maffesoli (2006). Maffesoli afirma que nosso mundo é tribal, que admite apenas verdades e concepções tribais. Porém é neo-tribal, pois diferente das tribos dos relatos etnográficos, as tribos urbanas de nossa nova modernidade, não são rigidamente controladas ou estruturadas. Hoje, ficar dentro ou fora de uma tribo é uma escolha individual, escolha que opera por meio do processo de auto-identificação. O próprio pertencimento a uma tribo é uma parte do processo de auto-definição individual. E assim, da mesma forma que o processo de construção de uma identidade, as neo-tribos estão sempre em fluxo contínuo.

Assim, para Bauman (2005) as identidades se tornam, em nosso mundo moderno-líquido, mais ambivalentes e líquidas. A continuidade para toda uma vida, assim como a coerência e univocidade das identidades, não são mais algo que exija grande preocupação. Os projetos de vida vitalícios, hoje, já não são bem acolhidos. Uma identidade coesa, fixada, solidamente construída é vista, atualmente, como um fardo, uma limitação da liberdade. Assim:

\footnotetext{
"Para a grande maioria dos habitantes do líquido mundo moderno, atitudes como cuidar da coesão, apegar-se às regras, agir de acordo com precedentes e manter-se fiel à lógica da continuidade, em vez de flutuar na onda das oportunidades mutáveis e de curta duração, não constituem opções promissoras." (BAUMAN, 2005, p.60)
}

\section{Considerações Finais}

Pudemos observar que a questão da identidade é um problema fundamental nas análises que Giddens e Bauman fazem do atual contexto da modernidade. Para 


\section{留ESE}

Revista Eletrônica dos Pós-Graduandos em Sociologia Política da UFSC

Vol. 5. n. 1 (1) agosto-dezembro/2008

ISSN 1806-5023

ambos os autores a identidade se torna um processo de construção constante. Mais do que um problema especificamente moderno, as identidades sempre estiveram no centro da vida social, porém, o que é trazido pela modernidade é um deslocamento do "foco" da identidade. Nas sociedades pós-tradicionais eram relativamente restritas às influências externas na formação das identidades individuais, essas se adaptavam fortemente a um contexto cultural local. Com a globalização há uma ruptura, e as identidades passam a estar em diálogo constante, deslocadas de um contexto único.

As categorias de reflexividade e liquidez, utilizadas pelos autores em questão, quando utilizadas para pensar as identidades, se referem aos mesmos problemas. Ambas são relativas às ampliadas possibilidades de construção de uma identidade individual, e mais do que isso, ambas apontam que numa alta modernidade, ou modernidade líquida, as identidades são constantemente reformuladas tendo em vista informações e contextos que também se encontram em constante reformulação. Os processos de globalização, dessa forma, ao acelerarem a mudança num contexto ampliado, também favorecem a mudança num contexto individual e cotidiano. Temos assim, em ambos autores, apesar de significativas diferenças na abordagem - com Giddens seguindo uma tradição mais "analítica", e Bauman uma linha de pensamento mais "crítica" - similitudes que nos permitem encarar às identidades como um processo incessante de reformulação e mudança.

\section{Referências Biliográficas}




\section{TSESE}

Revista Eletrônica dos Pós-Graduandos em Sociologia Política da UFSC

Vol. 5. n. 1 (1) agosto-dezembro/2008

ISSN 1806-5023

ARENDT, Hannah. A Condição Humana. $5^{\text {a }}$ ed. Rio de Janeiro: Forense Universitária, 1991.

AUGÉ, Marc. Não-Lugares: introdução a uma antropologia da supermodernidade. Campinas: Papirus, 1994.

BAUMAN, Zygmunt. Amor Líquido: sobre a fragilidade dos laços humanos. Rio de Janeiro: Jorge Zahar Editor, 2004.

BAUMAN, Zygmunt. Comunidade: a busca por segurança no mundo atual. Rio de Janeiro: J. Zahar Editor, 2003.

BAUMAN, Zygmunt. Identidade: entrevista à Benedetto Vecchi. Rio de Janeiro: J. Zahar Editor, 2005.

BAUMAN, Zygmunt. Modernidade e Ambivalência. 1.ed. Rio de Janeiro: J. Zahar Ed., 1999.

BAUMAN, Zygmunt. Modernidade Líquida. 1.ed. Rio de Janeiro: J. Zahar Ed., 2001.

BAUMAN, Zygmunt. O Mal-Estar da Pós-Modernidade. 1.ed. Rio de Janeiro: Jorge Zahar Ed., 1998.

BECK, Ulrich. Liberdade ou Capitalismo. São Paulo: editora UNESP, 2003.

BECK, Ulrich; GIDDENS, Anthony; LASH, Scott. Modernização Reflexiva. 1.ed. São Paulo: Ed. UNESP, 1997.

FOUCAULT, Michel. Microfísica do Poder. 24.ed. Rio de Janeiro: Graal, 2004.

FOUCAULT, Michel. Vigiar e Punir: nascimento da prisão. 30. ed. Petrópolis: Vozes, 2005 .

GIDDENS, Anthony. As Consequências da Modernidade. 2.ed. São Paulo: UNESP, 1991.

GIDDENS, Anthony. Modernidade e Identidade. 1.ed. Rio de Janeiro: Zahar Ed., 2002.

EmTese, Vol. 5 n. 1 (1), agosto-dezembro/2008, p. 01-31 


\section{䇰ESE}

Revista Eletrônica dos Pós-Graduandos em Sociologia Política da UFSC

Vol. 5. n. 1 (1) agosto-dezembro/2008

ISSN 1806-5023

GOFFMAN, Erving. A Representação do Eu na Vida Cotidiana. 12.ed. Petropólis: Vozes, 2004.

HALL, Stuart. A Identidade Cultural na Pós-Modernidade. 6.ed. Rio de Janeiro: DP\&A, 1998.

HORKHEIMER, Max; ADORNO, Theodor. A Dialética do Esclarecimento. $1^{\text {a }}$ ed. Rio de Janeiro: ZAHAR, 1985.

MAFFESOLI, Michel. O Tempo das Tribos: o declínio do individualismo nas sociedades de massa. 4.ed. Rio de Janeiro: Forense Universitária, 2006.

SENNETT, Richard. A Corrosão do Caráter: conseqüências pessoais do trabalho no novo capitalismo. 1. ed. Rio de Janeiro: Ed. Record, 1999. 